\title{
Nutrition change strategies: the new frontier
}

\author{
Milla McLachlan ${ }^{1, *}$ and James Garrett ${ }^{2}$ \\ ${ }^{1}$ Full Circle Consulting, PO Box 2276, Knysna 5760, South Africa: ${ }^{2}$ International Food Policy Research Institute, \\ 2033 K Street NW, Washington, DC, USA
}

Submitted 21 August 2006: Accepted 31 0ctober 2007: First published online 15 January 2008

\begin{abstract}
Objective: To advance understanding of nutrition change dynamics and strategies needed to tackle complex global nutrition challenges.

Design: Two frameworks, a descriptive framework of orders of change and a change model (Theory $\mathrm{U}$ ), are introduced to advance understanding of how to promote effective action on a complex social problem like nutrition. The descriptive framework explores the types of change pursued by four current global nutrition initiatives and the strategies they use to achieve their goals. Theory U provides a conceptual model to help understand breakthrough or transformative change, i.e. change that shifts the entire system.

Setting: The focus is on global and regional nutrition initiatives.

Results: Using the criteria of desired outcomes, purpose, participation and process, the orders of change framework categorizes programme strategies according to the levels of change likely to be achieved. Such a framework can help to structure conversations among actors about prerequisites for, and the likelihood of, transformative change. Theory U provides a conceptual framework to facilitate transformative change by providing insight into change processes and levers for action.

Conclusions: Nutrition is a complex social issue, and not only a biological or technical challenge. But nutritionists seldom inquire into the nature of changes required to achieve goals or the processes through which change occurs. Lack of understanding and failure to address such change processes directly mean that nutrition policies and programmes continue to fall short. There is a need to understand the dynamics of change in nutrition; to learn from current change experiences; and to create dynamic learning communities.
\end{abstract}

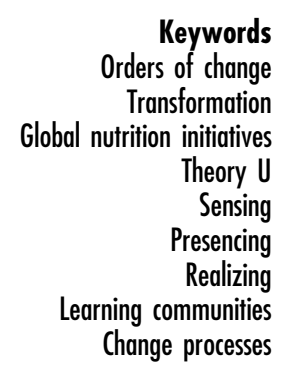

What will it take to achieve significant, sustainable and widespread change in global nutrition conditions? When will the world be nourishing for all? More than 30 years after the first global food conference where world leaders vowed that no child would go to bed hungry, malnutrition and hunger are still a daily reality for millions of people. While rapid gains have been made on some conditions and in some regions, almost 800 million people are chronically hungry, and stunted growth and micronutrient malnutrition continue to affect at least one in three children and their mothers ${ }^{(1)}$. At the same time, obesity and other diet-related conditions have emerged as leading causes of the chronic disease burden worldwide $^{(2)}$. In spite of heroic effort by scientists, policy makers, practitioners and households, the nourishing world continues to elude us.

Nutritionists realize that a narrow focus on the biological determinants of nutrition without equal attention to the institutional, political, economic and environmental dimensions of the problem will not bring about lasting change $^{(3)}$. The nutrition problem is a complex social issue, not only a technical challenge. The science of nutrition has expanded greatly during the past decade, as has the sophistication of research methodologies and the technical design of interventions. Efficacy studies continue to provide valuable information about what works at the biological level and under controlled circumstances. Maintaining momentum in scientific research is important, and testing new interventions must continue. However, the central challenge is not a shortage of technical knowledge about specific nutrition conditions, nor is there a shortage of proven interventions for specific nutrition problems ${ }^{(4)}$. Scaling up, doing more of what works, in more places, and more effectively, is essential. But given rapidly changing conditions, solutions that worked in the past may not be appropriate in the future. Making existing systems work is equally essential, but they too are subject to change. Relationships among government, civil society and business are changing rapidly and new governance systems are required ${ }^{(5)}$. 
While developing more technical solutions, scaling up interventions that work and strengthening existing systems are all important, these strategies are not sufficient to deal with the complexity of the nutrition situation today. There are too many places where, in spite of vigorous knowledge generation and application in policies and programmes, ongoing advocacy and system strengthening efforts, nutrition improvement has stagnated or been reversed. In vast regions of Africa, for example, malnutrition is on the increase; and in Asia and Latin America, the co-occurrence of under- and over-nutrition poses tough new challenges ${ }^{(1,6-9)}$.

More of the same is clearly not enough. It is time to look more closely at the change process itself, and how breakthrough change - change that shifts the entire system - can be facilitated. To accelerate progress, there needs to be a deeper understanding of the complexity of the nutrition situation, of the roles of individuals and organizations in creating, maintaining and resolving it, and of the kinds of change processes needed to address different nutrition dilemmas. Investment is needed in learning how change actually works, and how transformative change can be facilitated where it is needed. Such learning must happen during change processes as they occur. It requires reflection on participants' understanding of the problem, on how different groups (including donors and development agencies) contribute to maintaining the situation as it is, and on how specific activities change nutrition conditions, keep systems going or open them up for change. Learning about change itself is nutrition's new frontier.

\section{Nutrition and change}

Whether the focus is on increasing the effectiveness of interventions, improving systems or rethinking the entire nutrition enterprise, change is at the heart of the work public nutritionists do. Yet, curiously, there is little discussion of the models of social change that underlie the field and guide its thinking. Goals are stated in terms of change: 'reducing underweight', 'increasing the consumption of iodized salt' or 'decreasing morbidity and mortality'. Programmes are geared towards changing knowledge, attitudes and practices, and policies tackle underlying social, political and economic conditions to bring about desired changes. Researchers measure inputs and outputs and assess whether objectives are met. But they seldom inquire deeply into the nature of the changes required, the roles of different actors, or the processes through which change occurs. In policy and programme circles, the Triple A process of Assessment, Analysis and Action is widely used as a planning tool. It focuses primarily on gathering and interpreting objective data, and applying it to take action. It thus assumes an objective observer, outside the system under consideration. It is seldom used to consider subjective or interpersonal dimensions, such as the convictions and commitments of the planners themselves, or the norms that guide their interactions. It does not distinguish between different types or levels of change. The 'black box' of the change process thus remains largely unexplored - a missed opportunity for learning in the quest for the kind of changes that would create a nourishing world for everyone.

This 'blind spot' is not unique to nutrition. Practitioners and analysts confronting tough global challenges like HIV/AIDS, climate change, rural development, and water and sanitation also recognize the need to develop effective change processes and study their dynamics in order to accelerate social development and achieve lasting benefits $^{(10)}$. Experts argue, for example, that global issues like environmental degradation will not be resolved unless the predominant reductionistic problem-solving approach is replaced with more inclusive decisionmaking processes based on a vision of a sustainable future that everyone can share ${ }^{(11)}$. Drawing on management sciences, social psychology, sociology and anthropology, as well as on ancient wisdom traditions, social entrepreneurs in different regions are developing innovative new approaches to understanding and facilitating the kinds of change needed to resolve today's tough development challenges. These innovations cover a broad spectrum of social problems, ranging from global warming to HIV/ AIDS, and are being implemented at local, regional and global levels. For example, the HIV/AIDS Leadership for Results strategy, applied by the United Nations Development Programme since 2002, brings together leaders from business, government and civil society to build individual and shared commitment and develop breakthrough actions to address the underlying causes of the epidemic, as a catalyst for a vigorous ongoing response to $\mathrm{HIV} / \mathrm{AIDS}^{(12)}$. In a bold venture in the food sector, the Sustainable Food Lab assembled leaders from government, business, non-governmental organizations and farmers groups, to talk and work together to devise innovative, large-scale solutions for the global food system $^{(13)}$. Initial results indicate that these processes are transformative, leading to deeper commitment to the issues on the part of leaders, and resulting in innovations not tried before on such a large scale. Experiences like these and the conceptual frameworks that underlie them can inform an agenda for learning and action on change in nutrition.

The present paper introduces two frameworks, i.e. a descriptive framework of orders of change and a change model, the U-process, based on Theory U, as useful conceptual tools to advance understanding of nutrition change dynamics. It presents the descriptive framework of first-, second- and third-order change, which compares and contrasts different types of change, and provides conceptual tools to explore the prerequisites and 
practices needed to bring about higher orders of change. This framework is then used to explore the types of change pursued in four new global nutrition initiatives, and the strategies employed in these initiatives to achieve the changes they seek. Turning to the dynamics of the change process, it takes a closer look at the U-process, the change model that informs one of the four nutrition initiatives, the Partnership for Child Nutrition. The paper concludes that a joint exploration of change frameworks and models by leaders of programmes like these would yield valuable insights for developing robust change strategies to tackle the nutrition challenges that now confront the global nutrition community.

\section{First-, second- and third-order change}

One framework for learning about change differentiates among first-, second- and third-order change processes $^{(14)}$. It makes a distinction between processes that involve improving the performance of an existing system (first order), change processes that involve addressing shortcomings of a system (second order) and efforts that fundamentally rethink how an issue is conceptualized and the roles of all parties in addressing it (third order). First-, second- and third-order change can be distinguished in terms of desired outcomes, purposes, participants and processes.

First-order change. First-order change processes are used when the focus is on replicating proven solutions and extending the application of tried and tested solutions, with the aim to improve the effectiveness of an existing system. The process is largely focused on maintaining the status quo with regard to how the system functions; it replicates existing power structures and reinforces current role assignments of different actors. A nutrition example of first-order change is the ongoing effort to ensure that vitamin A capsules reach intended beneficiaries as part of immunization campaigns.
Second-order change. Reform is the defining characteristic of second-order change efforts. These efforts seek to reform existing systems to address shortcomings and better serve the needs of stakeholders. Second-order change processes open up the existing system to involve beneficiaries and other stakeholders in decision making and create a space in which dialogue can take place and alternative viewpoints are taken seriously. Government, business and civil society are engaged in interaction, but there is no attempt to change the roles assigned to each sector. Reforming procurement systems and incorporating the distribution of vitamin A capsules into routine services is an example of second-order change.

Third-order change. An openness to thoroughgoing change, including letting go of cherished programmes, arrangements, roles and rules, is characteristic of thirdorder change processes. These processes involve fundamentally rethinking issues, as well as the categories used to understand causes of the current situation. It requires readiness on the part of all participants to pay attention to roles played by themselves and others in the system, and a willingness to challenge conventional hierarchical decision-making structures. Participatory processes and networking structures are therefore commonly used in third-order change initiatives. Since government, business and civil society all play a role in creating, maintaining and resolving complex social issues, third-order change requires participation by representatives of each sector on an equal footing with the others (Table 1). Third-order nutrition change would, for example, involve re-conceptualizing micronutrient malnutrition, and rethinking the roles of government, business and civil society in addressing it. Table 2 provides additional nutrition examples.

In summary, first-, second- and third-order change processes differ from one another with regard to:

1. The kinds of knowledge and problem-solving approaches used. First-order change is characterized

Table 1 Orders of change in problem-solving initiatives ${ }^{(14)}$

\begin{tabular}{|c|c|c|c|}
\hline Criterion & First-order change & Second-order change & Third-order change \\
\hline Desired outcome & 'More (or less) of the same & Reform & Transformation \\
\hline Purpose & $\begin{array}{l}\text { To improve the performance of } \\
\text { the established system }\end{array}$ & $\begin{array}{l}\text { To change the system to address } \\
\text { shortcomings and respond to } \\
\text { the needs of stakeholders }\end{array}$ & $\begin{array}{l}\text { To redefine and address problems from a } \\
\text { whole-system perspective }\end{array}$ \\
\hline Participation & $\begin{array}{l}\text { Replicates the established } \\
\text { decision-making group and } \\
\text { power relationships }\end{array}$ & $\begin{array}{l}\text { Brings relevant stakeholders into } \\
\text { the problem-solving } \\
\text { conversation in ways that } \\
\text { enable them to influence the } \\
\text { decision-making process }\end{array}$ & $\begin{array}{l}\text { Creates a microcosm of the problem system, } \\
\text { with all participants coming in on an equal } \\
\text { footing as issue owners and decision makers }\end{array}$ \\
\hline Process & $\begin{array}{l}\text { Confirms existing rules. Preserves } \\
\text { the established power structure } \\
\text { and relationships among actors } \\
\text { in the system }\end{array}$ & $\begin{array}{l}\text { Opens existing rules to revision. } \\
\text { Suspends established power } \\
\text { relationships; promotes } \\
\text { authentic interactions; creates a } \\
\text { space for genuine reform of the } \\
\text { system }\end{array}$ & $\begin{array}{l}\text { Opens problems to creation of entirely new } \\
\text { ways of thinking about the issue. Promotes } \\
\text { transformation of relationships towards } \\
\text { whole-system awareness and identity; } \\
\text { promotes examination of the deep structures } \\
\text { that sustain the system; creates a space for } \\
\text { fundamental system change }\end{array}$ \\
\hline
\end{tabular}


Table 2 Examples of first-, second- and third-order nutritional change efforts

\begin{tabular}{|c|c|c|c|}
\hline $\begin{array}{l}\text { Nutrition } \\
\text { condition }\end{array}$ & First-order change & Second-order change & Third-order change \\
\hline $\begin{array}{l}\text { Vitamin A } \\
\text { deficiency/ } \\
\text { micronutrient } \\
\text { malnutrition }\end{array}$ & $\begin{array}{l}\text { Improve distribution of vitamin A } \\
\text { capsules using health system }\end{array}$ & $\begin{array}{l}\text { Implement integrated vitamin A } \\
\text { strategies; reform capsule } \\
\text { distribution system }\end{array}$ & $\begin{array}{l}\text { Rethink approach to micronutrient deficiency } \\
\text { control, with the involvement of all } \\
\text { stakeholders on equal footing in process }\end{array}$ \\
\hline Obesity & $\begin{array}{l}\text { Improve existing educational } \\
\text { campaigns and marketing } \\
\text { controls }\end{array}$ & $\begin{array}{l}\text { WHO strategy on Diet and } \\
\text { Physical Activity; strengthen } \\
\text { regulatory frameworks } \\
\text { regarding snack food marketing }\end{array}$ & $\begin{array}{l}\text { Rethink agricultural marketing, urban design } \\
\text { and educational approaches, regulatory } \\
\text { mechanisms and incentive structures, with } \\
\text { the involvement of all stakeholders on equal } \\
\text { footing }\end{array}$ \\
\hline $\begin{array}{l}\text { Infant and young } \\
\text { child nutrition }\end{array}$ & $\begin{array}{l}\text { Improve implementation of } \\
\text { existing nutrition programmes }\end{array}$ & $\begin{array}{l}\text { Development and enforcement of } \\
\text { the Code on Marketing of } \\
\text { Breast Milk Substitutes }\end{array}$ & $\begin{array}{l}\text { Rethink and redesign infant feeding, maternal } \\
\text { education, and related programmes, and } \\
\text { enforcement mechanisms, involving the } \\
\text { public and private sector and civil society }\end{array}$ \\
\hline
\end{tabular}

by linear, cause-and-effect technical reasoning, and generally applies known technical solutions to clearly defined problem situations. Second- and third-order change progressively broadens the type of knowledge considered relevant for addressing the issue, drawing on a wider range of disciplines and knowledgegenerating techniques to arrive at conclusions about required action. Whereas first-order change draws sharp distinctions between assessment, analysis and action, as separate and sequential processes, thirdorder change processes are characterized by an open, organic learning process approach.

2. The dynamics of the relationships between and among sectors, groups and individuals. First-order change processes accept the existing ordering of relationships among sectors and representatives of sectors as given, without opening them for debate. In second-order change processes there is a greater openness to reflect on the roles of different sectors, on notions of shared leadership and on complex networks of relationships among different actors. There is also room for discussion about the roles of different groups and potential for change in role assignment. In third-order change processes, nothing is 'given' and relationships among sectors can be fundamentally reshaped. In such 'whole-systems' approaches, there is a shared understanding that every stakeholder is part of the whole system, that there is interdependence, and that each sector is co-responsible for the desired outcomes.

3. How the individual relates to the change process and to the systems involved. Whereas in first-order change, the change process and the system to be changed are seen as largely external to the individual (be it analyst or manager), second-order change processes stimulate individuals to begin to reflect on their own roles in the system, and how their actions contribute to it. In thirdorder change, there is more explicit attention to and reflection on the role of the individual, and to how change at the individual level - in perceptions, intentions and actions, for example - directly influences the outcomes of the change process.

While much can be achieved through first- and secondorder change, observers of global change processes argue that today's complex global problems also require thirdorder change, involving the transformation of individuals, relationships and systemic patterns ${ }^{(14)}$. Given the multifaceted nature of change processes, ascribing superior outcomes to third-order change processes should be approached with care. Nevertheless, in cases where conventional approaches to problem solving repeatedly failed, third-order change strategies have shown great promise. For example, leaders and participants in the Mont Fleur Scenario project in South Africa, which brought together stakeholders from the entire political spectrum to envision a post-apartheid South Africa, and Guatemala's constitutional development process, coming after decades of conflict, both utilized third-order change processes. In these initiatives leaders participated in formal and informal meetings, took time to reflect deeply on their personal involvement in the systems they were trying to change, and together devised and tested concrete solutions. These activities led to significant benefits, including changed attitudes and improved relationships among different stakeholders that extended long after the life of the projects, and deeply shared commitment to finding lasting solutions to what had seemed to be intractable problems ${ }^{(15)}$.

Not every nutrition condition requires third-order change; neither can such approaches be implemented in all circumstances. In many situations, effective first-order change processes could rapidly improve access to needed nutritional inputs and improve knowledge and practices. In areas where scientific and technical knowledge about nutrition is lacking, and decisions have been made based on outdated traditional beliefs and conventional wisdom, the promotion and expansion of evidence-based interventions would be a great step forward and contribute significantly to improving nutrition conditions. Often, 
however, such first-order changes are not enough, and their 'imposition' from above through established decision-making structures may encounter resistance after a while. Dissatisfaction with service delivery systems often signals that it is time to take fresh approaches to the problem, and to reform the ways bureaucracies tackle nutrition problems. Such second-order change efforts present their own unique set of challenges, including rethinking how public and private sector entities engage with each other, what the rules of engagement are, and how the reform of the system could enhance nutrition outcomes.

Situations where known technical solutions and efforts at reforming the system have not delivered the necessary results or where conditions are changing so rapidly that conventional approaches are not appropriate may require a radical rethinking of the problem and demand a different kind of process to develop and implement solutions. Tackling iron-deficiency anaemia worldwide, and achieving significant reductions in the very high rates of childhood malnutrition in South Asia and parts of Africa, are examples of challenges that call for such rethinking. Decades of effort to make progress on these problems using available scientific knowledge and existing organizational arrangements have not yielded widespread significant results. The conditions have complex multiple causes and intervention strategies require action by a range of stakeholders. It is unlikely that first- and second-order change processes alone will be sufficient to bring about the change needed. In cases like these, experimenting with third-order change strategies could generate new insights and begin to shift the system that creates or prevents solutions to the problem.

Progress in improving nutrition conditions is more likely if the types of change necessary to achieve different goals can be identified, and first-, second- and third-order change processes are skilfully linked. Conscious application of a framework which distinguishes among different types of change should assist with selecting change strategies, and result in a more effective response to the complexity of the nutrition situation today. There is a new generation of nutrition programmes that employ, more or less explicitly, specific strategies to bring about secondand third-order change. The following section briefly introduces four of these nutrition initiatives, and uses the change-order framework to take a closer look at the change intentions of each initiative. The four initiatives are the Global Alliance for Improved Nutrition (GAIN), HarvestPlus, Partnership for Child Nutrition (PCN) and the Regional Network on AIDS, Rural Livelihoods and Food Security (RENEWAL). Although other nutrition projects have incorporated elements of the initiatives noted here, these merit special attention because of their larger-scale and systematic application of knowledge on change processes in a more recent context.
One of the initiatives, PCN, employs an explicit change model, the U-process model, as a technology to facilitate third-order change. The paper details this change model and the theory on which it is based, Theory $\mathrm{U}$, as one example of the kinds of models needed to facilitate thirdorder change. Shared learning processes among these programmes would result in new ways to approach change, new ways that are urgently needed to address the nutrition challenges of the 21st century.

\section{New nutrition initiatives}

Several global nutrition initiatives have been launched during the past five years. The New Nutrition Science Project, for example, seeks to re-conceptualize how nutrition science is understood and practised ${ }^{(16)}$. It adopts a systems perspective and proposed principles and processes to move from a narrow medical model to a more holistic approach. On the policy and programme front, there are efforts to develop new technological solutions, and to build capacity and rapidly scale up action to address global nutrition challenges. Implicitly or explicitly, these initiatives seek to come to terms with the complexity of the nutrition situation, be it through attention to the frameworks used to understand the problem, or through innovative partnership arrangements and participatory processes.

GAIN, launched at the UN General Assembly Special Session on Children in May 2002, aims to improve the nutritional status of one billion people, primarily through fortification of commonly consumed foods with vitamins and minerals ${ }^{(17)}$. At the global level, GAIN is governed by an international multi-sectoral board, supported by a technical secretariat. GAIN and the World Bank Institute spearheaded the formation of the Business Alliance for Food Fortification (BAFF), to provide a platform to strengthen the voice of the private sector, develop new financial mechanisms and business models for food fortification, and facilitate joint action by business, government and development agencies. At country level, GAIN supports formation of National Fortification Alliances as multi-stakeholder forums to guide the implementation of fortification strategies and programmes supported by GAIN and its partners. GAIN disburses grant funds through a competitive process and through a small grants scheme which addresses critical gaps and obstacles in food fortification efforts.

HarvestPlus $^{(18)}$, a challenge programme of the Consultative Group on International Agricultural Research (CGIAR), aims to reduce vitamin and mineral deficiencies among poor populations by developing and promoting biofortified crops as a low-cost, sustainable option. Biofortification involves selecting and breeding varieties of staple crops that are high in vitamins and minerals and have superior agronomic qualities, making them 
attractive for farmers to grow. HarvestPlus is an interdisciplinary global alliance of research and implementing institutions, coordinated by the International Center for Tropical Agriculture (CIAT) and the International Food Policy Research Institute (IFPRI). Other CGIAR research centres, national agricultural research systems and academic research institutes carry out the research, policy analysis and impact assessments, whereas civil society organizations and business partners provide linkages to consumers. By introducing nutritional considerations into plant breeding programmes and emphasizing the involvement of marketing intermediaries and consumers, HarvestPlus challenges conventional approaches to research management and knowledge dissemination, and serves to stimulate innovative partnerships among stakeholders.

The $\mathrm{PCN}^{(19)}$ is a global multi-sectoral partnership initiative which aims to facilitate breakthrough solutions to persistent nutrition problems. Initiated by the Synergos Institute, Unilever Corporation and UNICEF, the PCN's first country-based initiative was launched in India, under the auspices of a newly created local foundation, the Bhavishya Alliance. In its first project, the Maharashtra Change Lab, the Alliance used a distinct social technology - the U-process - to bring together representatives of public, private and civil society stakeholders in a microcosm of the nutrition system. This group engaged in an intense process that emphasized participants' personal commitment and openness to change, as well as their collective strength to change a situation. It involved a thoroughgoing analysis of the nutrition situation and generated a large number of innovative solutions that were then further developed, with the intention to bring the most promising innovations to scale.

RENEWAL $^{(20)}$ is a regional action research initiative in Africa. As a network which brings together food- and nutrition-oriented organizations (involving government, business and civil society) with partners involved in HIV and public health, it emphasizes local ownership and capacity building. RENEWAL seeks to foster linkages between researchers and policy makers, and between researchers from agriculture and public health - two fields that do not communicate much - while addressing key knowledge gaps on linkages between HIV and food and nutrition security. Activities consist of expert-led situation analyses, followed by multi-stakeholder consultations which set priorities for action research and make recommendations on local network governance. RENEWAL builds local research and communication capacity and facilitates interaction among partners at local, national and regional forums ${ }^{(21)}$.

The four initiatives share a commitment to doing things differently to achieve global nutrition goals. In addition to first-order change processes, which are routinely used to implement known technical solutions, the four initiatives also employ second-order change processes. Thus stakeholders from government, business and civil society participate in the design and decision-making processes, and the initiatives employ different strategies to build capacity to develop and disseminate new answers to the nutrition challenge. GAIN, for example, seeks to make the private sector a central player in the global effort to eliminate micronutrient malnutrition - an aspiration that requires change in the perceptions and actions of individuals in all three sectors, changes the dynamics between the sectors, and may demand rewriting some of the rules governing food quality and marketing. HarvestPlus seeks to broaden production goals in agriculture, by adding health objectives to plant breeding programmes. It also seeks to involve end users in the research and development process, thus bringing different perceptions to the table early on in the process.

The extent to which the initiatives use third-order change processes and achieve fundamental change in how systems operate needs to be studied empirically. The potential to transform how systems operate exists, to some extent, in all four initiatives. For example, BAFF, formed under the auspices of GAIN, creates a platform where representatives of public and private sector groups can build more open and transparent relationships, and address the underlying issues that hamper progress. Likewise, the National Fortification Alliances that are being set up in countries where GAIN supports fortification activities bring the public, private and civil society sectors together around a shared agenda. Further study is needed to determine whether and how these activities at global and national levels are changing the way malnutrition challenges are understood and addressed.

RENEWAL is structured as a network involving food and nutrition and health entities from the public, private and civil society sectors. It seeks to improve impact through locally prioritized action research and communication activities. Expert-led situation analyses are followed by multi-stakeholder consultations which set priorities for action research and make recommendations on local network governance. Local, regional and national stakeholder groups then use the research findings to shape action. Case studies of RENEWAL's activities in various countries could explore whether the focus on local priorities actually leads to fundamentally different understandings of the links between HIV/AIDS and food and nutrition security and change how systems respond to this complex challenge.

The PCN is explicit about pursuing third-order change. The immediate aim of the Maharashtra Change Lab, PCN's first country-based initiative implemented through the Bhavishya Alliance, is to significantly improve nutrition outcomes in five districts in Maharashtra. Through modelling new approaches, strengthening multi-sectoral partnerships and building individual and organizational 
Table 3 Approaches to achieving transformative change in nutrition initiatives

\begin{tabular}{|c|c|c|c|c|}
\hline Name & Mission & Strategy & Structure & Activities \\
\hline $\begin{array}{l}\text { Global Alliance } \\
\text { for Improved } \\
\text { Nutrition }\end{array}$ & $\begin{array}{l}\text { Build momentum to end } \\
\text { vitamin and mineral } \\
\text { deficiency, through } \\
\text { fortification, by } \\
\text { mobilizing government } \\
\text { and private sector } \\
\text { involvement. } \\
\text { Transformative change } \\
\text { potential implicit }\end{array}$ & $\begin{array}{l}\text { Brokering - drawing on } \\
\text { resources in each sector, } \\
\text { facilitating operational } \\
\text { partnerships, building } \\
\text { government and } \\
\text { business capacity and } \\
\text { consumer demand }\end{array}$ & $\begin{array}{l}\text { National Fortification } \\
\text { Alliances provide } \\
\text { opportunity for equal } \\
\text { participation, Business } \\
\text { Alliance for Food } \\
\text { Fortification promotes } \\
\text { business involvement }\end{array}$ & $\begin{array}{l}\text { Alliance activities at global } \\
\text { and national levels have } \\
\text { potential to generate } \\
\text { deeper commitment to } \\
\text { nutrition goals in all three } \\
\text { sectors }\end{array}$ \\
\hline HarvestPlus & $\begin{array}{l}\text { Harness the power of plant } \\
\text { breeding to end vitamin } \\
\text { and mineral deficiencies, } \\
\text { broaden focus of plant } \\
\text { breeding to include } \\
\text { health factors. } \\
\text { Transformative change } \\
\text { potential implicit }\end{array}$ & $\begin{array}{l}\text { Adopts an integrated food- } \\
\text { systems approach; } \\
\text { involves all relevant } \\
\text { stakeholders at various } \\
\text { levels in the system; } \\
\text { builds local capacity for } \\
\text { multi-sectoral work }\end{array}$ & $\begin{array}{l}\text { Expert-led interdisciplinary, } \\
\text { global alliance, involving } \\
\text { developed and } \\
\text { developing country } \\
\text { partners; business, } \\
\text { NGO, government and } \\
\text { research institutions }\end{array}$ & $\begin{array}{l}\text { Systems approach helps to } \\
\text { shift perspectives on } \\
\text { nutrition and how to } \\
\text { address it among } \\
\text { agriculturalists and } \\
\text { health personnel }\end{array}$ \\
\hline $\begin{array}{l}\text { Partnership for } \\
\text { Child Nutrition }\end{array}$ & $\begin{array}{l}\text { Aims to facilitate } \\
\text { breakthrough solutions } \\
\text { to persistent nutrition } \\
\text { problem. Creates } \\
\text { conditions to facilitate } \\
\text { new understanding of } \\
\text { problem at local, national } \\
\text { and global levels and } \\
\text { generate innovative } \\
\text { solutions }\end{array}$ & $\begin{array}{l}\text { Promoting cross-sectoral } \\
\text { collaboration - involves } \\
\text { and creates conditions } \\
\text { for collaboration across } \\
\text { sectoral boundaries, in } \\
\text { problem understanding, } \\
\text { solution generation and } \\
\text { implementation. Explicit } \\
\text { emphasis on } \\
\text { participants' personal } \\
\text { commitment and } \\
\text { openness to change }\end{array}$ & $\begin{array}{l}\text { Multi-stakeholder } \\
\text { partnership formed } \\
\text { through consultation to } \\
\text { ensure it represent the } \\
\text { system, 'champions' } \\
\text { from government, } \\
\text { business and civil } \\
\text { society provide overall } \\
\text { legitimacy to project, } \\
\text { 'Lab team' serves as } \\
\text { microcosm of the } \\
\text { nutrition system and } \\
\text { takes responsibility for } \\
\text { modelling and } \\
\text { disseminating a 'new } \\
\text { way of solving problems' }\end{array}$ & $\begin{array}{l}\text { Problem analysis, } \\
\text { reflection and action } \\
\text { involves microcosm of } \\
\text { whole system; } \\
\text { prototypes model 'new } \\
\text { reality' }\end{array}$ \\
\hline RENEWAL & $\begin{array}{l}\text { Implicit, to support new } \\
\text { ways of understanding } \\
\text { the linkages between } \\
\text { HIV/AIDS and food and } \\
\text { nutrition insecurity; build } \\
\text { capacity and improve } \\
\text { communication }\end{array}$ & $\begin{array}{l}\text { Explicitly adopts } \\
\text { multidisciplinary and } \\
\text { multi-sectoral approach, } \\
\text { involving representatives } \\
\text { of health and agricultural } \\
\text { ministries, research } \\
\text { organizations, national } \\
\text { AIDS commissions, } \\
\text { NGO, and people } \\
\text { directly affected by HIV/ } \\
\text { AIDS and food and } \\
\text { nutrition insecurity }\end{array}$ & $\begin{array}{l}\text { Regional networks of food- } \\
\text { and nutrition-oriented } \\
\text { organizations (involving } \\
\text { government, business } \\
\text { and civil society) with } \\
\text { partners in HIV/AIDS } \\
\text { and public health. Seeks } \\
\text { to improve impact } \\
\text { through locally prioritized } \\
\text { action research, } \\
\text { combined with improved } \\
\text { capacity and } \\
\text { communication }\end{array}$ & $\begin{array}{l}\text { Expert-led situation } \\
\text { analysis, followed by } \\
\text { multi-stakeholder } \\
\text { consultations which set } \\
\text { priorities for action } \\
\text { research and make } \\
\text { recommendations on } \\
\text { local network } \\
\text { governance. Studies } \\
\text { contracted, then } \\
\text { discussed in local, } \\
\text { national and regional } \\
\text { forums }\end{array}$ \\
\hline
\end{tabular}

NGO, non-governmental organization.

capacity, the Alliance seeks to influence how nutrition conditions are addressed throughout India, ultimately aiming to contribute to halving the rate of malnutrition by 2015, as envisaged in the Millennium Development Goals.

Table 3 summarizes the approaches used by the four initiatives to bring about change. Further analysis of the actual processes used in the four initiatives is needed to provide greater evidence of their effectiveness and to yield richer insights for theory and practice. Specifically, research should look at their impact on how the nutrition problem is understood, on individual and collective commitment to action, and on results, in order to assist ongoing efforts to develop appropriate change models to address malnutrition in the years ahead.

\section{The U-process: an example of a third-order change model}

The PCN applies an explicit change framework, based on a distinct transformative change model called the U-process. This section of the paper provides a brief introduction to the model and its application in the Maharashtra Change Lab, as an example of available change theories and lessons to be learned from applying such models to address complex nutrition issues.

The U-process model was developed by Otto Scharmer of the Massachusetts Institute of Technology ${ }^{(22)}$ and refined through action research by management practitioners and social theorists associated with the Society for Organizational Learning, Generon Consulting and the Synergos 
Institute. It is an example of an explicit change framework, based on a specific change theory (Theory U), designed to guide third-order change processes. The model has also been applied to health care renewal in Germany ${ }^{(23)}$, and the Sustainable Food Lab, a multi-stakeholder partnership initiative aimed at creating large-scale innovations towards a sustainable global food system ${ }^{(13)}$.

Theory U hypothesizes that sustainable, transformative change is a function of shifts in individual perceptions, perspectives and intentions, shifts in collective perceptions and intentions, and joint action on intentions. According to Theory $\mathrm{U}$, leaders need to respond to the complexity of current global problems by experiencing the issue directly, relating it to their own experiences and thoughts, and linking these deeper understandings to the knowledge that already exists in the local area where the problem is encountered ${ }^{(24)}$. The U-process provides a systematic process for doing so.

\section{The $U$-process model}

The U-process model is a social technology that seeks to facilitate third-order change. It is concerned with the individual's perceptions, values and actions, as well as those of the groups or society in general. Using a structured process of joint learning, reflection and action, the U-process seeks to build high-trust relationships among stakeholders, and strengthen the capacities of individuals and groups to bring about deep innovation and change in complex organizational and social systems. It utilizes both objective knowledge and subjective experiences. It links assessment, analysis and action, with emphasis on both individual and collective engagement. It emphasizes involving a carefully selected team of actors from organizations that are engaged in all aspects of the system that affects the problem and its solution. The approach systematically enables change in perceptions and perspectives, deepens conversations and shared commitments, and supports the development and implementation of novel responses to the problem.

\section{Applying the $U$-process model to nutrition: the Mabarashtra Change Lab}

Applied to nutrition, the U-process model represents a significant elaboration of the conventional Triple A model for nutrition change and widespread 'stakeholder analyses'. It is presented here to stimulate discussion about the kind of conceptual models needed to foster transformative forward-looking change in nutrition.

Confronted with the persistence of malnutrition in India, in spite of decades of dedicated efforts to improve the situation, the PCN and its Indian partners, through the Bhavishya Alliance, recognized that third-order change was needed and proposed to apply the U-process model to learn how this could be done.
As discussed earlier, a transformative change process involves change at individual, organizational and systemic level. Challenges at each level, if not addressed, can weaken the process. The concrete explication of the process which follows is meant to highlight these potential obstacles so they can be dealt with early on. Some specific concerns include stakeholders having different understandings of the issue, different opportunities and capacities to act, or considering the issue to be of greater or lesser importance. A weak or non-existent evidence base for action, or weak capacity or interest on the part of stakeholders to understand or use the evidence, can also pose challenges. In addition, stakeholders, particularly those who are principal agents of change, may not wish to let go of preconceptions, value the knowledge of others, or trust their actions. They may also fail to see the personal relevance of wider consultation or a more holistic approach or may ignore personal and institutional incentives to drive change. Finally, there is the need to demonstrate progress, in process or results, to stakeholders over time, without which they may conclude the approach is not working and is not useful.

Involving carefully selected representatives from the full range of stakeholders making up the system is important. In the Maharashtra Change Lab, civil society, government and business had to be represented in a balanced way, as all three sectors play a role in the nutrition system. The representatives needed to be open to change and to addressing partnership issues, and had to have the power to effect change in their organizations. While planners recognized the importance of community representation in the system, language barriers made this impractical, and it was decided to involve local people in specific activities during the course of the Change Lab's work. Two levels of involvement were created: (i) 'Change Lab members' were to be actively involved in the day-to-day operation of the project, for a three-month period*; and (ii) 'champions', senior-level decision makers and leaders committed to the goals of the Alliance, were to share their expertise and be involved in decision making on a more ad boc basis. Through an intensive networking process at the highest level of the relevant organizations, the Alliance was able to bring together a Change Lab group consisting of eight representatives from the corporate sector, eleven from civil society, and ten from government. A group of thirty-six champions, the majority from the non-governmental organizations sector, was also assembled. A group of 'esteemed guests', nutrition and management experts from different sectors, were invited to address the Lab

\footnotetext{
* As initially envisaged, the Change Lab was to stretch over a nine-month period. It soon became apparent that few organizations could spare a staff member for that length of time. With redesign, the Lab process was shortened to an intensive three-month period.
} 
team in the course of the process. The overall administration and management of the process was undertaken by a small executive team convened by the Bhavishya Alliance. The Change Lab process was facilitated by a team from Generon Consulting, assisted by four facilitators from India. A process evaluation was carried out by Tata Institute of Social Sciences ${ }^{(25)}$. Three broad objectives were pursued in the Maharashtra Change Lab: (i) to develop innovative initiatives to address the malnutrition problem, from conceptualizing the ideas to piloting the most promising initiatives; (ii) to build strong relationships among stakeholders involved in the nutrition system; and (iii) to develop individual and organizational capacity to help transform the nutrition system across India.

The U-process itself consists of three distinct phases, which this synopsis highlights: (i) 'sensing'; (ii) 'presencing'; and (iii) 'realizing'; and involves the development of seven capacities, in sequence. These are identified in Fig. 1. Concrete examples of these phases during the process of implementation of the Maharashtra Change Lab are discussed below.

\section{Sensing}

Sensing is the process of transforming perception, by carefully and thoroughly studying the current reality. In the model, it involves developing two capacities: 'suspending' and 'redirecting'. Understanding the nature of the problem, the first step in any change process, starts by putting existing scientific and experiential knowledge on the table. Often problem-solving processes go no further than applying existing knowledge to new problems, and do little systematic reflection on the underlying nature or causes. In a conscious effort to develop a deeper understanding of a problem, participants in the U-process are given the opportunity to reflect on their own perspectives - 'seeing their seeing'. They then begin to see not only their own perspective, but begin to take the perspective of others into account. They also begin to see elements of the system from a broader, holistic and interconnected perspective.

Participants are encouraged to recognize that these different perspectives are the result of disciplinary 'glasses', institutional positions (you see from where you sit), and life experiences. In the sensing phase of the U-process, participants look at the problem from all angles, suspend their habitual perceptions and judgements, listen closely, take the perspective of others, look at the whole picture, and see themselves as part of the system, standing in a specific relation to it. While scientific knowledge about the issue under consideration, e.g. child malnutrition, would be a key ingredient of knowing, other forms of knowing and experiencing are also brought into play in this phase. In its practical application, the sensing phase involves pooling participants' knowledge and perceptions of the current situation, beginning to reframe the questions and studying them together. Through a process of joint learning, including undertaking 'learning journeys' together to study the issue afresh, team members redefine the problem and formulate a shared understanding of it. Thus, the team moves from having a wide range of separate, often opposing, perspectives, to working together from the basis of a shared understanding.

In this phase, then, there are four basic steps: (i) putting available knowledge on the table; (ii) reflecting on one's own understanding, knowledge and experience as it relates to this problem and its solution; (iii) learning and

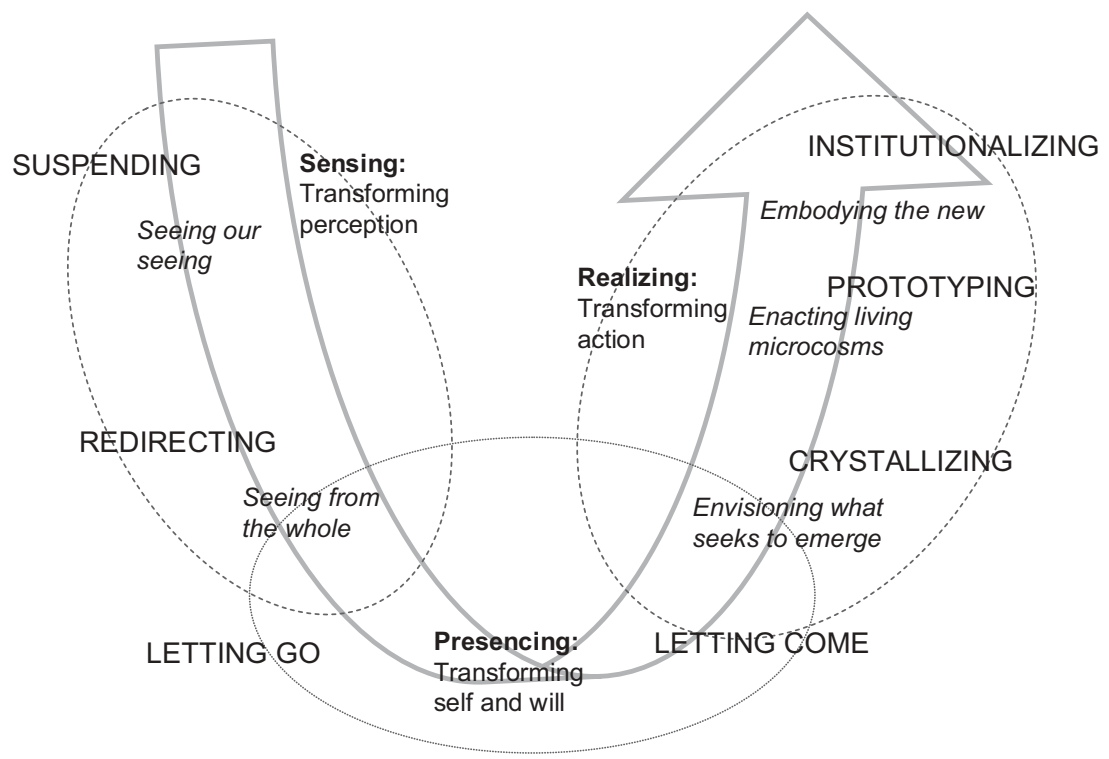

Fig. 1 Theory $U$ (based on Senge et al. ${ }^{(24)}$ ) 
appreciating how others might relate to the problem and its solution; and (iv) through sharing knowledge and experiences, coming to a common perception of the problem and possible solutions.

In the Maharashtra Change Lab, a week-long foundation workshop served as an introduction to the U-process. The Change Lab members were introduced to each other, participated in exercises to develop capacities to let go of preconceived ideas, to observe and listen without judgement and, through journaling and role play, learned to take different perspectives. Through interactive dialogue with esteemed guests they deepened their understanding of the nutrition situation. This was developed further during the second module, which consisted of week-long 'learning journeys'. Groups of participants lived in villages in five regions in Maharashtra, and engaged with community members at all levels. During the third module, participants undertook systematic study of nutrition programmes and delivery systems, through observing the work in specific programmes, and conducting desk research on programmes. The purpose was to develop a shared understanding of the underlying structure of the system, and where interventions might have the biggest impact. A variety of dialogue techniques was used to deepen conversations among the Lab team members. Conversations with esteemed guests and champions continued and Lab team members shared their first ideas for interventions with the champions.

\section{Presencing}

Phase two of the U-process involves developing a deeper understanding of what is going on and what individuals who make up the system have to do to change it. This phase in the model, which is considered its core and unique component, is called presencing ${ }^{(24)}$. It involves letting go of cherished notions of the issue, of previous perceptions of how to address it, and of emotional attachments to previously held beliefs, attitudes and perceptions about solutions. Through personal and group reflection, which may include spending time alone (e.g. in solo retreats lasting up to three days), the process seeks to give participants access to what is best described as 'inner knowing'. Self-reflection requires asking what the situation demands of oneself, or, in the words of Otto Scharmer, 'what wants to emerge through me?' Thus the knowledge gained during the first phase begins to connect with and energize inner knowledge and feelings, helping to generate new ideas about potential solutions. This involves opening oneself up to future possibilities, and envisioning new realities. Group interactions about what has been learned during the time of reflection can lead to 'breakthrough' innovations that are to be prototyped and piloted in the final stages of the U-process.

In the Maharashtra Change Lab, team members undertook a seven-day nature retreat in Uttaranchal to reflect individually and collectively on what they were being called to do, in the light of the evidence gathered so far. Group reflection exercises were followed by a threeday solo retreat. Participants then shared with their groups what they individually had to contribute to the Change Lab process. With this experience behind them, the group reviewed the action areas that had been identified so far. Participants reported finding the presencing phase pivotal for deepening their commitment to the process, and this was reflected in the quality of subsequent group processes and ideas emerging for new initiatives.

\section{Realizing}

In Phase three, realizing, the team translates the ideas from the presencing stage into prototype projects that can be quickly implemented and tested, guided by the same people who have been involved in conceptualizing the problem and generating likely solutions. Prototypes, as the name implies, are smaller versions of the envisaged future - therefore the projects model the new reality on a small scale. These ventures signal that a new way of doing things is possible. The prototypes that prove viable are then scaled up and institutionalized.

Rather than embarking on lengthy and detailed planning processes, prototyping involves learning by doing, to immediately put into practice the proposals formulated during the preceding phases. It applies the maxim, 'fail early and fail often', so that knowledge generation and learning continue throughout the process. In contrast to many other change processes, in which analysts assess and analyse the situation, planners plan and implementers implement, the U-process engages those who have been involved in the assessment and analysis and conceptualization phases directly in the action. They remain responsible for, and committed to, the prototyping and pilot testing and mainstreaming of the ventures selected for implementation.

In the Maharashtra project, initiative teams, consisting of participants in the Change Lab process, champions, and new collaborators from communities and organizations, worked on prototyping the initiatives over a fiveweek period. A module on rapid cycle prototyping gave the teams an opportunity to start testing their ideas. They also learned more about innovation and systemic issues. The next module consisted of testing and retesting initiatives through dialogue with communities, front-line workers and other stakeholders. On the basis of these discussions, the various proposals were recombined into four broad initiatives. At this stage, pilot planning could commence. Question and answer sessions were conducted to challenge the teams to clarify their proposals further. This also turned out to be a time for stocktaking, with intense dialogue about the roles of Lab team members, champions, facilitators, and the Bhavishya 
Alliance itself. Discussions were held to capture the lessons of the Change Lab up to that point, and to further clarify the role of the Bhavishya Alliance in the implementation of the initiatives. It was an opportunity to practise the U-process in rapid cycles, retreating for short periods to reflect and reconnect before generating solutions to issues. The last module consisted of presentations of the final proposals to the champions and deliberations on the way forward towards implementation of the chosen initiatives.

\section{Personal, interpersonal and systemic change dynamics in the $U$-process: lessons from the Mabarashtra Change Lab process}

Applying the U-process creates opportunities for thirdorder change to occur. The Maharashtra Change Lab process demonstrated the power of the model. It also highlighted some of the challenges inherent in pursuing third-order change. First, U-process activities create individual and group capacities to open up to different sources of information about an issue, to suspend judgement and to take other people's perspectives on the problem. In the Maharashtra project, participants learned to listen without judgement and to appreciate different perspectives on the nutrition problem. They had the opportunity to experience the problem first-hand through immersion in village processes, and were exposed to a range of viewpoints on the problem. However, it proved difficult to bring all participants to the same level of understanding on the technical dimensions of the nutrition problems. While participants found the dialogue sessions with esteemed guests enlightening, they made less use of the abundant written source material they received, and did not draw sufficiently on the knowledge of the nutrition experts in the team. Time constraints and the lack of nutrition expertise among the facilitators were seen as the chief reasons for this problem.

Second, through the selection of team members from government, business and civil society, team processes that stress democratic dialogue and decision making throughout the process, and a heavy emphasis on individual commitments, the U-process can challenge existing relationships among stakeholders in the system, and build more constructive relationships to make the system function more effectively. In the Maharashtra project, strong interpersonal relationships developed among the participants, particularly during the presencing phase. However, it proved difficult to overcome strongly held preconceived notions about the other sectors. At the outset there was little shared knowledge about the strengths of the various sectors, and not enough time was devoted to sharing such information during the first phase of the project. Over the course of time, greater trust in the corporate sector seemed to develop among government and civil society participants, but this was still not sufficient to fully utilize its expertise in the design of the initiatives. Participants also noted that the lack of involvement of affected communities in the Change Lab detracted from its transformative potential, because it did not sufficiently challenge the status quo with regard to relationships between 'recipients' and service delivery agencies.

Finally, the U-process pays attention to the source from which leaders act to deal with challenges and bring about change (see Fig. 2). The U-process creates opportunities to move beyond simply reacting in habitual ways by

1. Reacting/downloading

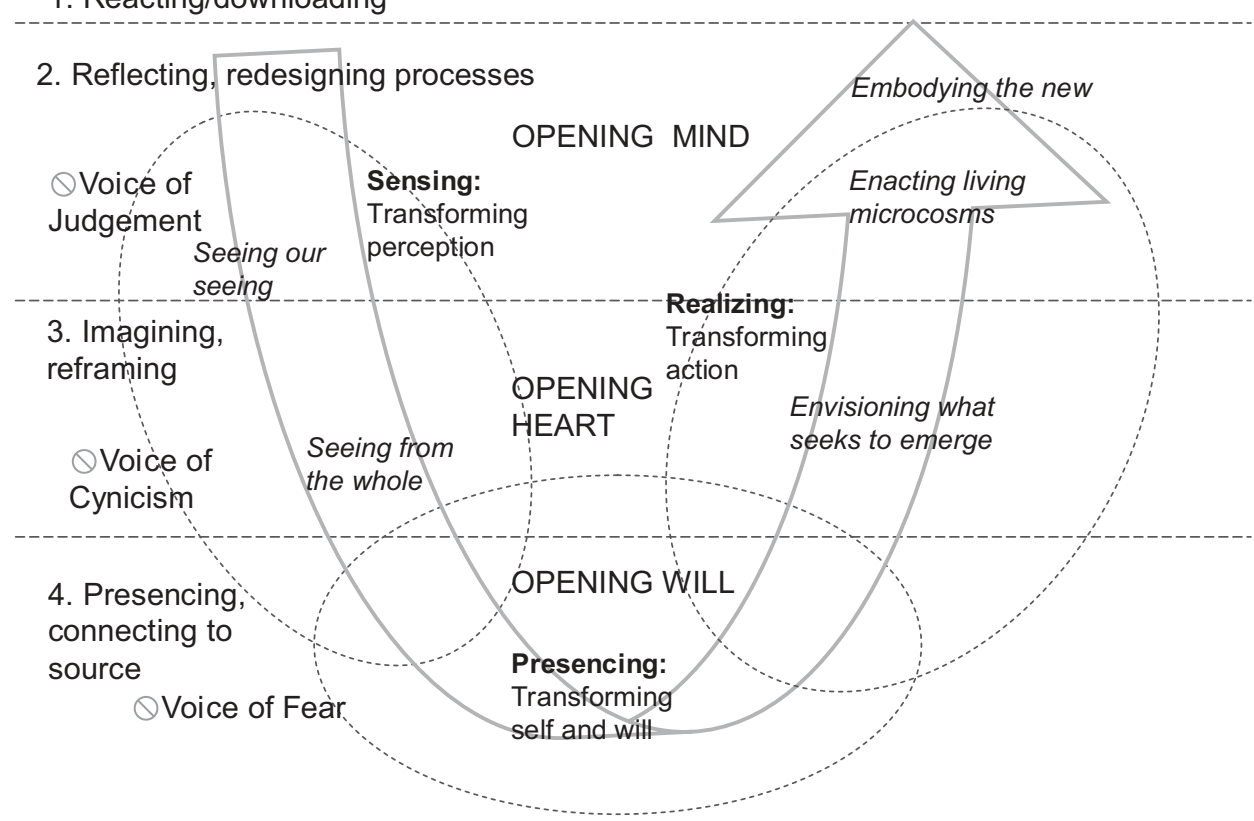

Fig. 2 Dealing with challenges (based on Scharmer ${ }^{(22)}$ ) 
drawing on solutions from past experience, to activate deeper sources of knowing for generating solutions to intractable problems. In addition to challenging participants to listen without judgement, to reflect on their own and other people's perspectives, and to begin to see that alternative interpretations can be valid, it makes individuals aware of their own power to help change the system. This process is not easy, because it requires inner changes. These include opening the mind to entertain new interpretations of reality and think more creatively; and opening the heart to take a personal interest in the issue. And most challenging is the need to be willing to act, often in new and untried ways.

In the Maharashtra project, Change Lab participants were challenged to draw from that deeper source and to make heart-felt personal commitments to implement innovative solutions to tackle the malnutrition problem. Their ability to do so was, however, hampered by a number of factors. First, some participants had limited power to change how their organizations functioned, because of their rank. When champions were also exposed to the U-process and thus developed a better understanding of the process, they were able to support Change Lab members more effectively. However, in very hierarchical organizations, these relationships remained quite formal, and may have limited the impact the Lab members could have on organizational change. A second impediment was the participants' partial understanding of the system as a whole, so that they could not envisage how their planned initiatives could be used to leverage system-wide change. More focused attention to selection criteria for Change Lab participants, and to the linkages between personal change, changes in interpersonal relationships and system-wide change throughout the Lab process, would help to overcome these obstacles. The evaluation team concluded that the Maharashtra Change Lab experience represented a significant step toward producing the needed radical changes to shift the nutrition system, and that the lessons from this pioneering experience would inform subsequent Change Lab processes in India.

\section{Conclusion}

Malnutrition has persisted as a complex social problem for far too long. Nutrition leaders must now turn their attention to the process of change to resolve the dilemma of malnutrition in a world of plenty. To support this shift in focus, two frameworks, a descriptive framework of orders of change and a change model (the U-process), have been introduced in the present paper as conceptual tools to advance understanding of nutrition change dynamics. As its application to four new global nutrition initiatives demonstrates, the concept of first-, second- and third-order change can help to structure conversations about what is needed to bring about higher orders of change. The U-process, the change model that informs the PCN, provides an example of the kinds of change frameworks needed to move the agenda forward. Lessons from the application of the U-process in the Maharashtra Change Lab demonstrate the opportunities and challenges that can be expected by those who are bold enough to pursue innovative approaches to solving the global nutrition problem. A learning community among leaders of such programmes would give them the opportunity to make their deep change goals more explicit, to name and refine the changes they are trying to achieve, and would help to make these innovative change processes more effective.

\section{References}

1. Standing Committee on Nutrition (2004) Fifth Report on the World Nutrition Situation. Geneva: United Nations System.

2. World Health Organization (2007) Obesity. http:// www.who.int/topics/obesity/en/ (accessed November 2007).

3. Leitzmann C \& Cannon G (2005) Dimensions, domains and principles of the new nutrition science. Public Health Nutr 8, 787-794.

4. Gillespie S, McLachlan M \& Shrimpton R (editors) (2003) Combating Malnutrition: Time to Act. Washington, DC: World Bank.

5. Haddad L \& Pelletier D (2003) The Nutrition Policy Process. A Proposal for a Global and Regional Research Program. Draft. Washington, DC: International Food Policy Research Institute.

6. Garrett JL \& Ruel MT (2005) Stunted child-overweight mother pairs: prevalence and association with economic development and urbanization. Food Nutr Bull 26, 209-221.

7. Gragnolati M, Shekar M, Das Gupta M \& Lee Y (2005) India's Undernourished Children: A Call for Reform and Action. HNP Discussion Paper. Washington, DC: World Bank.

8. Lobstein T, Baur L \& Uauy R (2004) Obesity in children and young people: a crisis in public health. Obes Rev $\mathbf{5}$, Suppl. 1, 4-9.

9. Rosengrant MW, Cline SA, Li W, Sulser TB \& ValmonteSantos RA (2005) Facing Alternative Futures: Prospects For and Paths To Food Security in Africa. 2020 Africa Conference Brief no 17. Washington, DC: International Food Policy Research Institute.

10. Rischard JF (2002) High Noon. 20 Global Problems 20 Years To Solve Them. New York: Basic Books.

11. Ehrenfeld J (2004) Searching for sustainability: no quick fix. Reflections: The SoL Journal 5, 8.

12. Sharma M, Reid S, Sarr CF, Gueye M \& Henderson A (2005) Leadership Development Programme Strategy Note. HIV/ AIDS Group, Bureau for Development Policy. New York: United Nations Development Programme.

13. Sustainablefood.org (undated) Homepage on the Internet. Vermont: Sustainable Food Laboratory; available at http:// www.sustainablefood.org (accessed December 2005).

14. Pruitt B \& Waddell S (2005) Dialogic Approaches to Global Challenges: Moving From 'Dialogue Fatigue' to Dialogic Change Processes. Working Paper prepared for the Generative Dialogue Project. http://www.generative dialogue.org/ 
15. Kahane A (2004) Solving Tough Problems. San Francisco, CA: Berrett-Koehler Publishers, Inc.

16. Leitzmann C \& Cannon G (editors) (2005) The new nutrition science project. Public Health Nutr 8, 667-800.

17. Gainhealth.org (undated) Homepage on the Internet. Geneva: Global Alliance for Improved Nutrition; available from http://www.gainhealth.org (accessed January 2006).

18. Harvestplus.org (undated) Homepage on the Internet. Washington, DC: HarvestPlus; available from http:// www.harvestplus.org (accessed February 2006).

19. Synergos.org (2007) Homepage on the Internet. New York: The Synergos Institute; available from http://www.synergos. org/ (accessed October 2007).

20. International Food Policy Research Institute (2006) About RENEWAL. http://www.ifpri.org/renewal/ (accessed January 2006).
21. Loevinsohn M \& Gillespie S (2003) HIV/AIDS, Food Security, and Rural Livelihoods: Understanding and Responding. Food Consumption and Nutrition Division Discussion Paper no. 157. Washington, DC: International Food Policy Research Institute.

22. Scharmer CO (2007) Theory U: Leading From The Future As It Emerges. Cambridge, MA: Society for Organizational Learning.

23. Kaeufer K, Scharmer CO \& Versteegen U (2003) Breathing life into a dying system. Reflections: The SoL Journal 5 (3), $1-10$.

24. Senge P, Scharmer CO, Jaworski J \& Flowers BS (2004) Presence: Human Purpose and the Field of the Future. Cambridge, MA: Society for Organizational Learning.

25. Datta V \& Sengupta J (2006) An Evaluation Report of the Maharashtra Change Lab Process. Report submitted to Bhavishya Alliance, Navi, Mumbai. 